\title{
Research Note: On the Magnitude of Error in the Calculation of Mean Room Surface Exitance
}

James Duff

Technological University Dublin, james.duff@arup.com

Follow this and additional works at: https://arrow.tudublin.ie/engscheleart2

Part of the Electrical and Computer Engineering Commons

\section{Recommended Citation}

Duff, J. (2016, August 3). Research Note: On the magnitude of error in the calculation of mean room surface exitance. Lighting Research \& Technology. SAGE Publications. doi:10.1177/1477153516659519

This Article is brought to you for free and open access by the School of Electrical and Electronic Engineering at ARROW@TU Dublin. It has been accepted for inclusion in Articles by an authorized administrator of ARROW@TU Dublin. For more information, please contact arrow.admin@tudublin.ie, aisling.coyne@tudublin.ie, gerard.connolly@tudublin.ie.

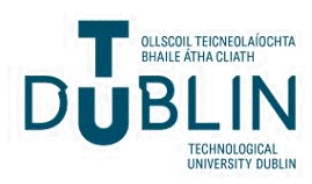




\title{
Research Note: On the magnitude of error in the calculation of mean room surface exitance
}

\author{
J Duff PhD \\ Arup Lighting and Dublin Institute of Technology, Dublin, Ireland
}

Short title: Error in the calculation of MRSE

Received 26 August 2015; Revised 11 June 2016; Accepted

Two formulae currently exist for calculating mean room surface exitance. This research note explains and demonstrates that one of these formulae is erroneous under certain conditions and stresses that the alternative expression should generally be used for computing mean room surface exitance.

Address for correspondence: James Duff, Arup, 50 Ringsend Road, Dublin 4, Ireland. E-mail: james.duff@arup.com

\section{Background}

Cuttle has proposed mean room surface exitance (MRSE) as a metric that may estimate the perceived brightness of an indoor lit environment. ${ }^{1}$ MRSE is defined as "the measure of average illuminance at all points within a space due to reflected light from the room surfaces, with direct light from either the luminaires or windows excluded". ${ }^{2}$ In that same paper, Cuttle introduces the concept of MRSE through a thought exercise and from this, mathematically defines MRSE as: 


$$
M R S E=\frac{F R F}{A_{\propto}}
$$

Where $F R F$ is the first reflected luminous flux, this being equal to the sum of the direct luminous flux, $E_{S(d)}$, reflected from each surface of area, $A_{s}$, and reflectance, $\rho_{s}$ :

$$
F R F=\sum E_{S(d)} A_{S} \rho_{S}
$$

$A_{\propto}$ is the room absorptance, this being the sum of the surface areas, $A_{S}$, times their absorptance values, where absorptance is given by one minus reflectance:

$$
A \alpha=\sum A_{S}\left(1-\rho_{S}\right)
$$

Equation (1) provides a simplistic and insightful way for lighting designers to relate the distribution of direct luminous flux to the total quantity of luminous flux within a space, but it is not without problems. In the thought exercise previously mentioned, Cuttle used an imaginary space and this space always had uniform surface reflectances, i.e. the floor, walls and ceiling had the same reflectance value. When each surface has the same reflectance, how the $F R F$ is distributed is irrelevant, but when the reflectances of surfaces differ, then the directional distribution of the $F R F$ becomes problematic and the validity of the expression lapses. This happens because the luminous flux emitted from any given surface cannot be incident on that surface, and furthermore, its incidence on any other surface will depend on the geometric relationship between the two items, in addition to their reflectances. In other words, a precise solution needs to encompass, not only the spatial distribution of the first reflection, but also every subsequent inter-reflection, as the outcome is dependent upon the geometric and reflectance relationships of the room surfaces. 
Raynham $^{3}$ has used a combination of transfer factors ${ }^{4}$ and utilisation factors to estimate MRSE with hand calculations, but more complex spaces, and even general calculations, are more easily dealt with using lighting analysis software that can readily account for a high number of inter-reflections, such as Radiance. Considering calculation of an almost infinite number of inter-reflections to be possible, and using a reasonable assumption that all surfaces within a space are Lambertian diffusers, MRSE can alternatively be defined by the sum of the area-weighted exitance values within a space, divided by the total room surface area:

$$
M R S E=\frac{\sum M_{S} A_{S}}{\sum A_{S}}
$$

Where $M_{S}$ is the mean exitance of each surface within the space, given by the product of the mean surface luminance, $L_{S}$, and pi, $\pi$ :

$$
M_{S}=L_{S} \pi
$$

\section{The magnitude of error}

So, there are two formulae that can be used to determine MRSE; the first, equation (1), is straightforward to calculate, but relies on all room surface reflectances being identical to maintain accuracy and the second, equation (4), is complex to calculate but will produce reliable results. To quickly investigate the magnitude of error in equation (1), some calculations have been carried out with Radiance using an imaginary space. The space was 5 $\mathrm{m}$ in width and breath and $3 \mathrm{~m}$ in height, with a single pendant suspended at the centre of the space (1.5 m from the ceiling) that emitted 5000 lumens through a Lambertian distribution, either entirely as uplight or downlight. Note that this is the total luminaire lumen output, exclusive of a light output ratio. Equation (1) was applied by setting surface reflectances to 
zero, thus simulating the direct luminous flux on each surface, recording this, then post processing the numbers using equations (2) and (3). A previously written script ${ }^{5}$ was ran to compute MRSE using equation (4). This script applies equation (5), whilst ignoring direct luminous flux from luminaires, then post processing to calculate MRSE. Table 1 shows the percentage level of error in equation (1), calculated over a selection of room surface reflectance values that all have an average of 50\%.

It can be observed that the error experienced using equation (1) is reasonable when typical room surface reflectances are used and the luminous flux is directed mostly onto surfaces of high reflectance, but nonetheless, this error is enough to highlight the shortcomings of the expression. The error also has potential to increase when the geometry is varied beyond the simple cube tested here. Whilst equation (1) will most likely continue to serve as a teaching aid, and perhaps for lighting designers who understand its limitations and find benefit in using it to devise hierarchies; the calculation and measurement of MRSE for

use in research, lighting standards or general illumination engineering should endeavour to apply equation (4) and this should be computed using appropriate methods and software programs.

\section{Funding}

\section{References}

1. Cuttle C. A new direction for general lighting practice. Lighting Research and Technology, 2013; 45(1): 22-39.

2. Cuttle C. Towards the third stage of the lighting profession. Lighting Research and Technology, 2010; 42(1): 73-93.

3. Raynham P. Room lighting in the absence of a defined visual task and the impact of mean room surface exitance. Lighting Research and Technology 2016; 48(2): 190-204. 
4. Raynham PJ, Bean AR. Calculation of transfer factors in the European utilization factor method. Lighting Research and Technology, 2006; 38: 341-357.

5. Duff J, Antonutto G, Torres S. On the calculation and measurement of mean room surface exitance. Lighting Research and Technology 2016: 48(3): 384-388. 
Table 1. The percentage error between calculations using both MRSE formulae and a selection of room surface reflectance values.

\begin{tabular}{|c|c|c|c|c|}
\hline $\begin{array}{l}\text { Equation } \\
\text { Used }\end{array}$ & $\begin{array}{l}\text { Surface Reflectances } \\
\text { (ceiling/walls/floor) }\end{array}$ & Light Distribution & $\begin{array}{l}\text { Mean Room Surface } \\
\text { Exitance }\left(\mathbf{l m} / \mathbf{m}^{2}\right)\end{array}$ & $\begin{array}{l}\text { Percentage } \\
\text { Error (\%) }\end{array}$ \\
\hline (1) & \multirow{2}{*}{$50 \% / 50 \% / 50 \%$} & Downlight & 45.45 & \multirow{2}{*}{0} \\
\hline (4) & & Downlight & 45.45 & \\
\hline (1) & \multirow{2}{*}{$50 \% / 50 \% / 50 \%$} & Uplight & 45.45 & \multirow{2}{*}{0} \\
\hline (4) & & Uplight & 45.45 & \\
\hline (1) & \multirow{2}{*}{$60 \% / 50 \% / 40 \%$} & Downlight & 38.8 & \multirow{2}{*}{0.8} \\
\hline (4) & & Downlight & 39.1 & \\
\hline (1) & \multirow{2}{*}{$60 \% / 50 \% / 40 \%$} & Uplight & 52.55 & \multirow{2}{*}{1.15} \\
\hline (4) & & Uplight & 51.95 & \\
\hline (1) & \multirow{2}{*}{$70 \% / 50 \% / 30 \%$} & Downlight & 31.9 & \multirow{2}{*}{2.45} \\
\hline (4) & & Downlight & 32.7 & \\
\hline (1) & \multirow{2}{*}{$70 \% / 50 \% / 30 \%$} & Uplight & 59.4 & \multirow{2}{*}{7.6} \\
\hline (4) & & Uplight & 55.2 & \\
\hline (1) & \multirow{2}{*}{$80 \%$ / 50\% / 20\% } & Downlight & 25.1 & \multirow{2}{*}{3.8} \\
\hline (4) & & Downlight & 26.1 & \\
\hline (1) & \multirow{2}{*}{$80 \% / 50 \%$ / 20\% } & Uplight & 66.3 & \multirow{2}{*}{11.0} \\
\hline (4) & & Uplight & 59.7 & \\
\hline (1) & \multirow{2}{*}{$90 \% / 50 \% / 10 \%$} & Downlight & 18.2 & \multirow{2}{*}{4.9} \\
\hline (4) & & Downlight & 17.35 & \\
\hline (1) & \multirow{2}{*}{$90 \% / 50 \% / 10 \%$} & Uplight & 73.1 & \multirow{2}{*}{17.7} \\
\hline (4) & & Uplight & 62.1 & \\
\hline
\end{tabular}

